\title{
A RELAÇÃO ENTRE PROFESSOR E ALUNO NO PROCESSO DE PRODUÇÃO DE VÍDEO EM SALA DE AULA
}

\author{
VANESSA OECHSLER, docente de Matemática, IFSC Câmpus Gaspar, \\ vanessa.oechsler@ifsc.edu.br \\ DANIELLE MANERICH, aluna Técnico Integrado em Química, IFSC Câmpus Gaspar, \\ danielle.manerich0901@ hotmail.com \\ FELIPE MATHEUS NOGUEIRA DA SILVA, aluno do Técnico Integrado em \\ Informática, IFSC Câmpus Gaspar, fe_matheus@hotmail.com
}

\begin{abstract}
Resumo
Este artigo, resultado de uma pesquisa de iniciação científica com alunos do Ensino Médio, explora a relação entre professor e aluno em aulas onde a produção de vídeo é o foco do trabalho. A produção de vídeos em sala de aula consiste em algumas etapas, como escolha e pesquisa do tema, elaboração de roteiro, gravação e edição das cenas. Em cada uma dessas etapas o aluno tem o papel de protagonista, decidindo a forma como o vídeo será produzido e como o conteúdo será explorado. O professor tem o papel de mediador e, por meio do diálogo, leva os alunos a refletir sobre as escolhas. Ao final do processo, por meio desse diálogo horizontal, há uma produção de conhecimento tanto por parte dos alunos (conhecimento matemático) quanto por parte do professor (conhecimento tecnológico).
\end{abstract}

Palavras-chaves: diálogo, conteúdo matemático, conhecimento tecnológico

\begin{abstract}
This article, the result of a scientific initiation research with high school students, explores the relationship between teacher and student in classes where video production is the focus of the work. The production of videos in the classroom consists in some steps, as selection and research of the topic of video production, elaboration of the script, recording and editing the scenes. In each of these stages, student has the role of protagonist, deciding how the video will be produced and how the content will be explored. Teacher has the role of mediator and, through dialogue, leads the students to reflect on the choices. At the end of the process, through this horizontal dialogue, there is a production of knowledge both by the students (mathematical knowledge) and by the teacher (technological knowledge).
\end{abstract}

Keywords: dialogue, mathematical content, technological knowledge

\section{1 - INTRODUÇÃO}

O uso de vídeos por alunos, tanto em sala de aula, quanto em casa, vem crescendo a cada ano. De acordo com a pesquisa realizada pela empresa Google, intitulada "Pesquisa Video Viewers" de 2017, 86\% de todos os entrevistados assistem a vídeos postados na Internet, utilizando primordialmente o YouTube. Desses visualizadores de vídeos, 65\% 
acessam vídeos para aprender alguma coisa, incluindo nessa porcentagem os alunos que buscam vídeos para sanar suas dúvidas de conteúdo. Surge um questionamento: se os alunos já fazem uso de vídeos, como pode ser o uso desses vídeos em sala de aula?

Borba e Oechsler (2018) realizaram uma pesquisa sobre essa utilização. Segundo os autores, o uso de vídeos em sala de aula pode ser dividido em três modalidades: (i) registrar lições para posterior análise do processo de ensino e aprendizagem; (ii) vídeos disponíveis em plataformas educacionais ou mídias sociais como material didático; (iii) produção de vídeo por alunos e professores em sala de aula (BORBA; OECHSLER, 2018). A modalidade (i) é utilizada primordialmente em pesquisa acadêmica, para analisar a prática do professor e o processo de aprendizagem do aluno. Faz-se uma gravação das aulas e uma posterior análise dessas imagens.

A modalidade (ii) é utilizada quando professores exibem vídeos disponíveis em plataformas. Esses vídeos são exibidos aos alunos que, normalmente, possuem uma atividade posterior a fazer, para discutir os conceitos e conhecimentos explorados no vídeo. Esse tipo de uso de vídeo na educação deve ter cautela por parte do professor, que precisa ter um objetivo em sua aplicação. Moran (1995) ressalta os cuidados com o uso de vídeos em sala de aula, para que eles não sejam uma forma de "tapar um buraco da aula", sem planejamento ou ligação com a matéria. Para auxiliar nessa escolha do vídeo pelo professor, Tena (2014, p. 78, tradução nossa) sugere os seguintes questionamentos:

1. Os conteúdos são coerentes do ponto de vista científico?

2. Está atualizado?

3. Os objetivos estão claros?

4. Adapta-se às características dos alunos?

5. O vocabulário é compreensível?

6. É tecnicamente atrativo?

7. O tempo é adequado às características dos meus alunos?

8. Propicia a realização de atividades posteriores? ${ }^{1}$

A modalidade (iii) ainda não é uma prática comum nas escolas (BORBA; OECHSLER, 2018), mas vem crescendo com o fácil acesso dos alunos e professores a celulares que permitem a gravação e edição das imagens e com pesquisas desenvolvidas na área que envolvem a produção de vídeos por alunos e estimulam o seu compartilhamento em Festivais (DOMINGUES; BORBA, 2018; PEREIRA; BRIGNOL; CEZAR, 2018).

A prática com produção de vídeos estudantis consegue preencher um "vazio" existente entre o aluno e o professor, onde parece que um é o detentor do saber e o outro um recipiente a ser depositado com informações (FREIRE, 2014). Este artigo, fruto de uma pesquisa realizada no Instituto Federal de Santa Catarina (IFSC) Câmpus Gaspar com alunos do Ensino Médio Técnico, tem o objetivo de investigar a modificação na relação entre

${ }^{1} 1 . ¿$ ¿Los contenidos son coherentes desde un punto de vista científico?

2 ¿Está actualizado?

3 ¿Están claramente expresados los objetivos que se persiguen?

4 ¿Se adapta a las características de mis alumnos?

5 ¿El vocabulario es comprensible o necesito realizar algunas adaptaciones?

6 ¿Es técnicamente atractivo?

7 ¿Su tiempo es adecuado a las características de mis alumnos?

8 ¿Propicia la realización de actividades posteriores? 
professor e aluno na sala de aula, identificando como a produção de vídeos pode promover um ensino com foco no aluno, em que o professor é o mediador do processo.

\section{2 - A PRODUÇÃo DE VÍDEOS E A DINÂMICA DA SALA DE AULA}

A produção de vídeos em sala de aula não sustenta um estilo de educação em que "o educador aparece como seu indiscutível agente, como o seu real sujeito, cuja tarefa indeclinável é "encher" os educandos dos conteúdos de sua narração." (FREIRE, 2014, p.79, grifos do autor). Neste modelo, denominado por Freire (2014) de educação bancária, o professor é o único detentor do saber e os alunos são vasilhas vazias que devem ser preenchidas com o conhecimento do professor. Em uma educação deste tipo, não há diálogo nem educação reflexiva, sendo muito difícil haver metodologias diferenciadas, como a produção de vídeos, por exemplo.

Em uma atividade de produção de vídeos, a dinâmica da sala de aula se modifica. Aluno e professor trabalham em conjunto, buscando um objetivo comum: a produção do vídeo. E, nesse processo de trabalho, vários são os momentos de diálogo, reflexão e negociação que ocorrem tanto entre alunos, quanto entre os alunos e o professor. Não há um único detentor do saber. Cada um contribui com os seus conhecimentos no processo de produção do vídeo, dialogando em todos os momentos.

O diálogo, nesse processo, é visto como uma conversação que tem como objetivo construir novos significados (ALRØ; SKOVSMOSE, 2006). É uma relação horizontal, "em que a confiança de um polo no outro é consequência óbvia" (FREIRE, 2014, p.113). Não há um único detentor do saber. "Testemunhar a abertura aos outros, a disponibilidade curiosa à vida, a seus desafios, são saberes necessários à pratica educativa.” (FREIRE, 1996, p. 135136). Em uma prática baseada no diálogo, cada um compartilha seus saberes e, em uma reflexão conjunta, esses conhecimentos são discutidos e novos conhecimentos são produzidos.

Percebe-se, em atividades que prezam pelo diálogo e pela reflexão, como é o caso da produção dos vídeos, o papel de protagonista dos alunos. Eles deixam de ser os depósitos para serem os atores do processo educacional. Decidem como o vídeo será produzido, quais técnicas utilizar, como explorar o conteúdo, entre outras ações. O professor é o mediador do processo, levando o aluno a refletir sobre suas decisões visando, no final do processo, a produção do conhecimento, o que caracteriza uma metodologia ativa de ensino. "As metodologias ativas dão ênfase ao papel protagonista do aluno, ao seu envolvimento direto, participativo e reflexivo em todas as etapas do processo, experimentando, desenhando, criando, com orientação do professor;" (MORAN, 2018, p. 4).

O papel do professor, em uma prática pedagógica voltada à metodologias ativas, é o de mediador, orientador, que gerará as perguntas e reflexões necessárias aos alunos para a execução da atividade e promoção do conhecimento. Se, no processo de produção do vídeo o aluno decide de que forma explorará o conteúdo, ao professor cabe a tarefa de acompanhar esse processo, indagando o aluno sobre suas escolhas, levando-o a refletir qual o melhor modo de explorar o conteúdo. De acordo com Watanabe, Baldoria e Amaral (2018, p. 3), colocar o aluno "como protagonista do seu conhecimento a partir da produção do vídeo é dar-lhe autonomia, orientação e motivação para aprender".

Na próxima seção detalharemos a metodologia do trabalho, explorando as etapas de produção de vídeo, o que ilustrará o papel de protagonista dos alunos, uma vez que, em todas 
as etapas, as decisões são tomadas por eles, por meio de reflexão, diálogo e negociações entre os membros do grupo.

\section{3 - METODOLOGIA}

Essa pesquisa foi desenvolvida com três turmas de alunos dos Cursos Técnicos Integrados (curso onde o aluno faz o ensino médio junto com o curso técnico) em Química e Informática do Instituto Federal de Santa Catarina (IFSC) Câmpus Gaspar. A atividade consistiu na produção de vídeos, pelos alunos, na unidade curricular de Matemática explorando temas como análise combinatória, probabilidade e sistemas lineares.

A metodologia de produção de vídeos em sala de aula seguiu o modelo disponibilizado por Oechsler, Fontes e Borba (2017): (i) Conversa com alunos e apresentação de tipos de vídeos; (ii) Escolha e pesquisa do tema da produção de vídeos; (iii) Elaboração do roteiro; (iv) Gravação das cenas; (v) Edição das imagens; (vi) Divulgação dos vídeos.

A primeira etapa para a elaboração dos vídeos foi feita através de vídeos apresentados em sala de aula pela professora. Os vídeos, produzidos na pesquisa de Oechsler $(2018)^{2}$, foram criados por outros estudantes para servir como inspiração aos alunos. Esses vídeos apresentavam temas matemáticos distintos, assim como diferentes métodos de exibição, sendo produzidos com material didático, utilizando animações, inspirado em vídeo aula, entre outros.

Logo após a exibição dos vídeos, foi realizada uma conversa com os alunos para determinação do tema a ser abordado em vídeo. Em uma das turmas o tema foi Análise Combinatória e/ou Probabilidade e na outra Sistemas Lineares, temas que os alunos estavam estudando no semestre na unidade curricular de Matemática. Após essa delimitação, os alunos realizaram uma pesquisa do conteúdo a ser explorado no vídeo para, na aula seguinte elaborar o roteiro.

O objetivo do roteiro é detalhar o que será abordado em vídeo, o que será utilizado para a sua produção e aspectos gerais como música, local de gravação e observações importantes. "O roteiro tem uma linguagem própria - que se destina a orientar a equipe de produção nas filmagens - e divide o vídeo em várias cenas com o objetivo de informar textualmente - o leitor a respeito daquilo que o espectador verá/ouvirá no vídeo." (VARGAS; ROCHA; FREIRE, 2007, p. 3). Nessa etapa os alunos discutiram suas ideias de vídeo e de como explorar o assunto na forma audiovisual, detalhando os passos a serem seguidos na gravação das cenas.

A partir desses passos, os alunos passaram à etapa de gravação das cenas. Dependendo do tipo de vídeo, gravaram imagens com câmeras digitais ou de celular, usaram aplicativos de animação (Vyond e Animaker), tiraram fotos para utilizar aplicativos de inserção de movimento, entre outros. Todas essas cenas foram armazenadas e editadas em uma aula seguinte.

Esse processo foi realizado no laboratório de informática da escola, utilizando softwares gratuitos de edição que a escola já apresentava instalado nos computadores (Movie Maker e Openshot). Alguns alunos, com uma pesquisa a parte, utilizaram outros aplicativos no qual atendiam suas necessidades, mas que também eram gratuitos.

${ }^{2}$ Os vídeos utilizados nesta etapa podem ser encontrados em:

https://www.youtube.com/watch?v=T02s_FTTqZM\&list=PLiBUAR5Cdi60GspUuuH_DpZkW_dv28V8D 
A última etapa do processo foi a exibição dos vídeos para a própria turma, que fez apontamentos sobre os materiais, indicando pontos positivos e sugestões de melhorias. Embasados nessas considerações, os alunos foram convidados a encaminhar os vídeos ao II Festival de Vídeos Digitais e Educação Matemática, como forma de divulgação do trabalho.

As etapas descritas acima foram gravadas e posteriormente transcritas, consistindo, juntamente com o diário de campo e vídeos produzidos, os dados da pesquisa. Trata-se de uma pesquisa qualitativa, em que o foco principal de análise é o processo envolvido na produção dos vídeos, observando-se a dinâmica da sala de aula quando uma atividade dessas é utilizada. Na próxima seção exploraremos alguns pontos que foram observados durante o processo de produção e transcrição dos dados no que se refere à dinâmica da sala de aula e o papel de alunos e professores nesse processo.

\section{4 - RESULTADOS E DISCUSSÃO}

Com base nos dados da pesquisa, percebe-se, durante o processo de produção do vídeo, uma troca de experiências entre professor e alunos, cada um explorando o seu conhecimento. Vamos relatar as discussões ocorridas em dois vídeos: (i) Sistemas Lineares ${ }^{3}$ e (ii) Análise combinatória na escolha de roupas ${ }^{4}$.

No vídeo (i) as alunas elaboraram um vídeo envolvendo um problema de Sistemas Lineares tendo como cenário o arranjo produtivo local da cidade onde residem: venda de produtos de moda íntima e praia. As alunas residem em Ilhota (SC) capital nacional da moda íntima e praia e, por este motivo, resolveram explorar esse assunto no vídeo. Tentaram problematizar a compra de calcinhas e sutiã, no atacado e varejo, nas lojas da cidade. Para isso, montaram o seguinte problema:

"Um comerciante de moda íntima e praia, ficou sabendo sobre a cidade de Ilhota, localizada em Santa Catarina, a qual é capital da moda intima e moda praia. Com o intuito de buscar as melhores peças por um custo econômico e de grande quantidade, $o$ comerciante buscou pelas lojas $A, B$ e $C$ por serem conhecidas pelo fato de seus preços $e$ alta qualidade dos tecidos. A loja A, apresentou calcinhas no valor de $R \$ 6,00$ no varejo e $R \$ 4,50$ no atacado, sutiã no valor de $R \$ 18,00$ no varejo e $R \$ 17,00$ no atacado e o conjunto a $R \$ 25,00$ no varejo e $R \$ 23,00$ no atacado. A loja $B$, apresentou a calcinha no valor de $R \$ 4,50$ no varejo e $R \$ 4,00$ o atacado, o sutia no valor de $R \$ 18,00$ no varejo e $R \$ 17,50$ no atacado, o conjunto custava $R \$ 24,00$ no varejo e $R \$ 22,00$ no atacado. A loja $C$ apresentou as calcinhas no valor de $R \$ 7,00$ no varejo e $R \$ 5,50$ no atacado, sutia no valor de $R \$ 23,00$ no varejo e $R \$ 22,50$ no atacado. Sabendo que a quantidade comprada em todas as lojas é a mesma, determine qual é a quantidade de produtos que o comerciante vai levar na loja mais barata"

Esse problema foi descrito no roteiro do grupo e entregue à professora. $\mathrm{Na}$ aula seguinte, as alunas e a professora conversaram sobre o problema. A professora questionou as alunas sobre a pergunta do problema, indagando quais dados utilizariam e qual cálculo realizariam para solucioná-lo. Ao reler o problema e discuti-lo entre si, as alunas perceberam que ali havia apenas dados das lojas, mas não uma problematização que permitisse a solução de um sistema linear. Refletiram sobre a questão e perceberam que, para responder qual a

\footnotetext{
${ }^{3}$ Disponível em: https://www.youtube.com/watch?v=Xe9-

0doZd4I\&t=1s\&list=PLBk_fDZRmOEEh4Tjv8OnR8UKCOTu5BUW4\&index=2

${ }^{4}$ Disponível em: https://www.youtube.com/watch?v=TdlT_VBCgAM\&list=PLBk_fDZRmOEHhUIxY144rrp9_m8aydUf\&index $=3 \& \mathrm{t}=73 \mathrm{~s}$
} 
quantidade de produtos que o comerciante iria levar, era necessário saber o valor gasto em cada loja. Dessa forma, alteraram para o seguinte problema:

"Um comerciante ouviu falar sobre a cidade de Ilhota, localizada em Santa Catarina, a qual é capital da moda íntima e moda praia. Com o intuito de buscar pelas melhores peças por um custo econômico acessível, o comerciante buscou pelas lojas, $A, B$ e $C$, conhecidas por seus preços e qualidades nos seus produtos. $O$ comerciante buscou por calcinhas, nesse sistema linear, representados pela variável $X$, sutiãs representados pela variável $Y$ e conjuntos, representados pela variável $Z$. A loja A, apresentou calcinhas nos valores de $R \$ 4,50$, sutiãs por $R \$ 17,00$ e conjuntos por $R \$ 23,00$. A loja B, apresentou calcinhas por $R \$ 4,00$, sutiãs por $R \$ 17,50$ e conjuntos por $R \$ 22,00$. A loja $C$ apresentou calcinhas por $R \$ 5,50$, sutia por $R \$ 22,50$ e conjuntos por $R \$ 27,00$. Sabendo que a quantidade de produtos comprada nas 3 lojas é a mesma, vamos determinar os valores de $X, Y$ e $Z$, sabendo que os valores gastos na loja $X$, foi de $R \$$ 6.750,00, na loja $Y, R \$ 6.550,00$ e na loja $Z, R \$ 8.200,00$." [problema apresentado e resolvido no vídeo Sistemas Lineares].

Neste relato é possível perceber o papel de mediador da professora. As alunas decidiram o conteúdo a ser exposto no vídeo e apresentaram uma proposta no roteiro. Ao ler o problema, a professora percebeu que não havia uma pergunta a ser respondida, levando esse problema ao grupo, para que eles percebessem a inconsistência e buscassem caminhos para solucioná-la. A professora não fez a mudança e apresentou ao grupo, e sim mostrou a inconsistência e incentivou o diálogo e a reflexão para resolver o problema. Percebe-se que houve um diálogo horizontal (FREIRE, 2014) com vistas à produção do conhecimento (ALR $\varnothing$; SKOVSMOSE, 2006). A professora usou o seu conhecimento do conteúdo para estimular a produção do conhecimento por parte dos alunos.

A partir da elaboração do problema envolvendo sistemas lineares, o grupo percebeu quais os elementos necessários para a resolução do problema. E, posteriormente, após uma discussão entre os membros do grupo, foi decidido que, para elaborar um problema deste conteúdo, são necessárias as incógnitas (que, neste caso, são as quantidades de peças adquiridas) e $\mathrm{o}$ resultado (oriundo dos preços pesquisados pelos integrantes). Consequentemente, também perceberam que, para a elaboração de uma questão envolvendo três incógnitas, são necessárias, no mínimo, três equações. Isso atesta que o grupo precisou se apropriar da definição de sistemas lineares para poder elaborar o problema e resolvê-lo.

No vídeo (ii) as alunas optaram por discutir o conceito de Princípio Fundamental da Contagem em um problema de escolha de roupas para ir a uma festa. Elas encenaram a discussão na escola, percebendo que a Matemática pode auxiliá-las na montagem das opções de roupa para ir a uma festa (quadro 1).

Quadro 1: Imagens e transcrição do áudio de trechos do vídeo "Análise Combinatória na escolha de roupas" em que uma das alunas expõe seu problema e a outra aluna mostra como a Matemática pode auxiliar na resolução do problema

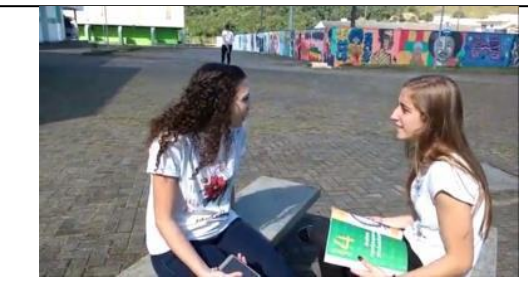

$(0: 00-0: 40)$
Aluna 1: Oi amiga

Aluna 2: $\mathrm{Oi}$

Aluna 1: Tudo bom?

Aluna 2: Tudo

Aluna 1: Então, né. Eu tô precisando de uma ajuda assim, sabe? Eu vou ter uma festa semana que vem e eu não sei nem que roupa que eu ia assim... Eu tava olhando lá em casa... Tenho muita roupa. Não sei. Será que tu poderias me ajudar, assim, com Matemática, ver quantas possibilidades que eu tenho, pra ajudar...

Aluna 2: Claro, eu tô justamente aprendendo isso na minha aula de Matemática. 


\begin{tabular}{|c|c|}
\hline 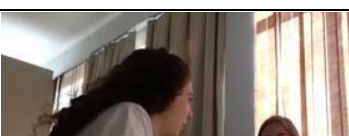 & $\begin{array}{l}\text { Aluna 2: O conteúdo que eu tô aprendendo em Matemática é } \\
\text { Análise Combinatória, que é o ramo da Matemática que analisa as } \\
\text { possibilidades e combinações. }\end{array}$ \\
\hline$(0: 40-0: 50)$ & \\
\hline$(1: 46-2: 59)$ & $\begin{array}{l}\text { Maria foi convidada para uma festa na casa da sua amiga Júlia. } \\
\text { Chegando o dia da festa Maria se depara com um problema. Ela } \\
\text { não sabe com qual roupa ela vai. Ela tem } 3 \text { saias, } 2 \text { blusas, } 2 \text { bolsas } \\
\text { e } 2 \text { sapatos. Quais são as diferentes possibilidades que Maria tem } \\
\text { para ir à festa? } \\
\text { [Resolução] } \\
\text { Resultado: } 24 \text { possibilidades }\end{array}$ \\
\hline
\end{tabular}

Fonte: dados da pesquisa

As alunas, com base no livro didático adotado na escola, tentaram explicar a resolução do problema de quantas possibilidades diferentes a aluna teria para ir à festa para a qual foi convidada. No vídeo, a explicação é feita da forma como é transcrita no quadro 2.

Quadro 2: Imagens e transcrição do áudio de trechos do vídeo "Análise Combinatória na escolha de roupas" em que a aluna explica o Princípio Fundamental da Contagem

\begin{tabular}{|c|l|l|}
\hline & $\begin{array}{l}\text { Aluna 2: Aqui é o nosso livro que vai falar sobre Análise } \\
\text { Combinatória. Na Análise Combinatória tem o Princípio } \\
\text { Fundamental da Contagem, onde tu multiplica x por y. x são as tuas } \\
\text { opções, que no teu caso seriam as tuas roupas, e y são as escolhas } \\
\text { que tu vai ter, né. Aí tu vai pegar assim. Tu tem lá } 5 \text { blusas, } 6 \text { calças } \\
\text { e 2 sapatos, por exemplo. Tu vai multiplicar 5 por 6, e depois por } 2 . \\
\text { Que daí tu vai obter a quantidade de possibilidades de escolha de } \\
\text { roupa, pra tu ir para a festa. }\end{array}$ \\
\hline $0: 57-1: 46$
\end{tabular}

Fonte: dados da pesquisa

No entanto, a explicação da aluna não está correta. A definição de quem é x e y não é a mesma explorada pelos matemáticos. E, ao assistir o vídeo, a professora percebeu esse erro e levou para discutir com a dupla, fazendo-as refletir sobre o conceito matemático explorado.

Professora: $O$ exemplo não tá errado, a única coisa... eu tô pensando no jeito que tu explicou, opção... entendeu? $O$ que é o $X$ e o que é o $Y$ porque parece que são coisas diferentes e na verdade tudo são as opções porque tu tens as blusas, tens as calças, tens os sapatos. Entendeu? É só isso, não é o exemplo que tá errado.

Aluna 2: A, então a gente pode fazer um negócio assim, ó... não, a gente pode fazer um negócio assim ó [ a aluna mostra como pode explorar essa questão no vídeo].

[...]

Aluna 2: E daí aparece um balão, tipo...

Professora: Uhum

Aluna 2: É... "Pensando bem, os dois são opções, são as duas opções"

Professora: Que aí a gente vê certinho a definição aqui. Ó, aqui tá a definição de Princípio Fundamental da Contagem. Se o evento é composto de duas etapas sucessivas $\boldsymbol{e}$ independente de tal maneira que o número de possibilidades da primeira é $\boldsymbol{m}$ e para cada possibilidade o primeiro número de possibilidade da segunda é $\boldsymbol{n}$ então o número total de possibilidades do evento ocorrido é dado pelo produto de $\boldsymbol{m}$ vezes $\boldsymbol{n}$. 
Aluna 1: Tipo, é o que a gente vai falar, tipo, $\boldsymbol{x}$ é uma coisa e $\boldsymbol{y}$ é outro. Tipo assim, a, $\boldsymbol{x}$ é... são as minhas opções aí eu tenho cinco opções desse, seis desse e duas desse e o n... como é que eu vou explicar?

Professora: Na verdade não, o $\boldsymbol{x}$ e o teu $\boldsymbol{y}$... $\boldsymbol{x}$ são as opções de blusas, o $\boldsymbol{y}$ são as opções de calça e aí tu vai multiplicar os dois.

Aluna 1: E o z é a opção de sapatos.

Observa-se que a professora apontou a inconsistência na explicação e levou as alunas a refletir sobre o conteúdo e o que poderiam fazer para alterá-lo. Como elas já haviam gravado as cenas e, uma nova gravação dispenderia mais tempo, as alunas optaram por arrumar, na edição, com a inserção de um balão explicativo, o que foi apresentado de forma equivocada no vídeo. Assim, enquanto a aluna explica o conteúdo, aparece o balão que mostra a definição correta (Figura 1)

Figura 1: Imagem do vídeo "Análise Combinatória na escolha de roupas" onde aparece a correção da explicação de Princípio Fundamental da Contagem no balão

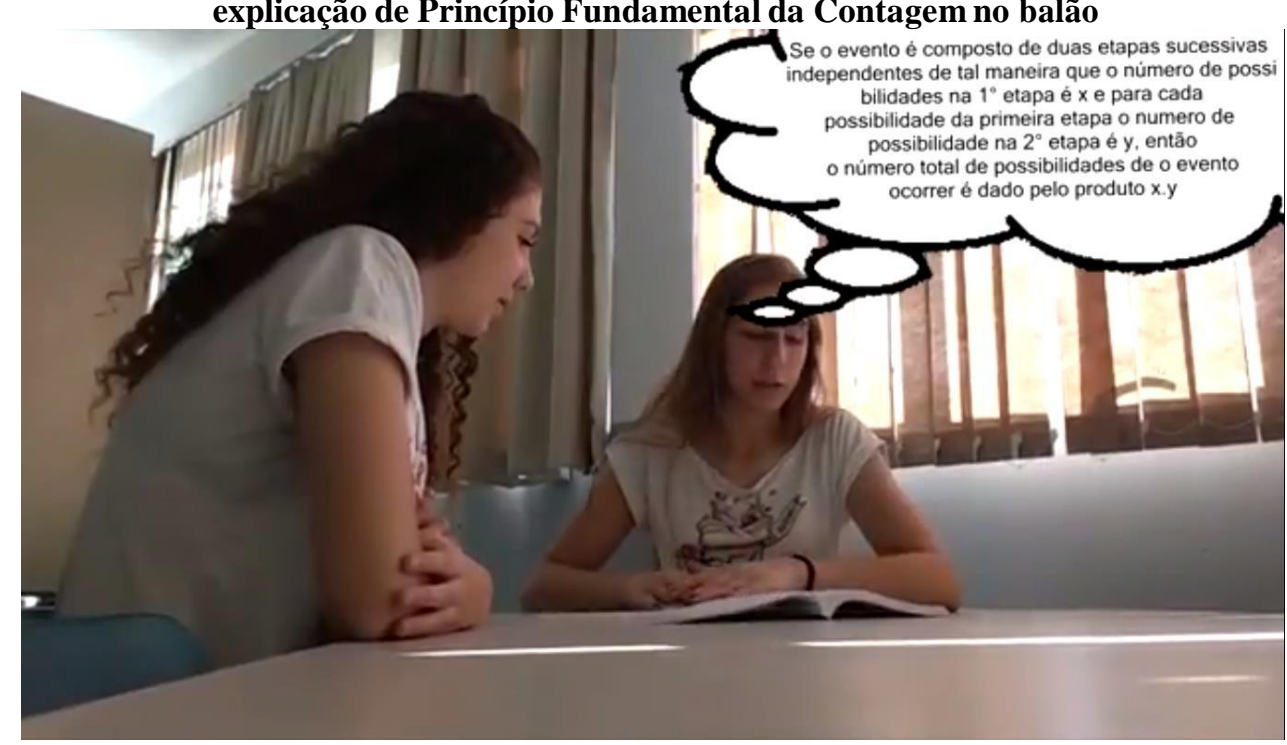

Fonte: dados da pesquisa

Nota-se a importância da troca de experiências e conhecimentos envolvendo alunos e professores quando ambas as partes colaboram para chegar em um determinado objetivo. A professora, no vídeo (ii) novamente apontou inconsistências de conteúdo, mostrando às alunas que havia um erro de interpretação no conceito de Princípio Fundamental da Contagem. As alunas não haviam percebido que o evento possuía etapas independentes e que cada etapa (no caso, as blusas, as saias, as bolsas, etc.) representava uma "uma letra" da definição. Após discutir com a professora, buscar novamente a definição no livro e dialogar entre si, as alunas perceberam o erro. No entanto, como não havia tempo hábil para realizar uma nova gravação, as alunas optaram por inserir um balão (Figura 1) no vídeo com a explicação correta, usando um recurso tecnológico para resolver o problema. No diálogo entre professora e alunos, percebe-se que a professora discutiu o conteúdo matemático e as alunas utilizaram seus conhecimentos tecnológicos para sanar o problema apresentado. Houve uma troca de saberes nesse diálogo, produzindo conhecimento tanto para alunos (conhecimento matemático) quanto para a professora (solução tecnológica no vídeo).

O uso da tecnologia no meio escolar é extremamente vantajoso quando ambas as partes do processo educacional colaboram para alcançar algum objetivo em comum. $\mathrm{O}$ uso de celulares e a produção de vídeos educacionais trazem essa percepção de forma muito clara e objetiva, modificando a dinâmica da sala de aula, atribuindo ao aluno o papel de 
protagonista do seu conhecimento, dando-lhe autonomia e orientação para aprender (WATANABE; BALDORIA; AMARAL, 2018). Ao professor cabe o papel de mediador e orientador desse processo, levando o aluno a refletir sobre suas escolhas, discutindo a melhor forma de produzir significado.

\section{5 - CONCLUSÃO}

Observou-se na atividade de produção de vídeos, o papel de protagonista do estudante. Ele decidiu o que explorar do conteúdo (resolução de problema de roupas íntimas e cálculo das possibilidades da montagem de um traje para uma festa) e a forma de abordagem do vídeo (animação, gravação das cenas na escola). Ou seja, o aluno foi o centro do processo de aprendizagem, decidindo quais passos seguir (MORAN, 2018), modificando a dinâmica da sala de aula bancária. O professor teve o papel de mediador, ao discutir os conteúdos explorados, sugerindo reflexões e apontando caminhos.

O diálogo horizontal (FREIRE, 2014) perpassou todo o processo de produção tanto entre os alunos que, ao trabalhar em grupo precisaram discutir e negociar suas ações, quanto entre alunos e professor, sendo que este último contribuía com o aspecto teórico do conteúdo e os primeiros com os aspectos tecnológicos, havendo uma troca e, consequentemente, produção de conhecimento.

"O desafio freiriano é construirmos novos saberes a partir da situação dialógica que provoca a interação e a partilha de mundos diferentes, mas que comungam do sonho e da esperança de juntos construirmos nosso ser mais." (ZITKOSKI, 2010, p. 118, grifos do autor) Podemos utilizar esse desafio de Freire e pensar no aspecto da produção dos vídeos. Nessa atividade, a partir de um diálogo horizontal, professor e alunos interagem e partilham mundos diferentes, em que cada um possui o seu conhecimento, seja do conteúdo matemático ou do conhecimento técnico de produção de vídeo. E, nesse diálogo, reflexão e discussão, os atores envolvidos no processo comungam da ideia de produzir juntos o vídeo, e, também, produzir conhecimento.

Na prática com produção de vídeos a onisciência de saberes não existe, pois cada um contribui com o seu conhecimento. O aluno utiliza de seu conhecimento em ferramentas digitais, mesmo que amadoras, para guiar a parte prática da ação. $\mathrm{O}$ professor contribui com a parte educacional, complementando as discussões dos alunos sobre o conteúdo didático explorado no vídeo. Percebe-se uma interação e troca de conhecimento entre ambas as partes, resultando em um convívio homogêneo onde não há superioridade em nenhuma das extremidades e o diálogo contribui na produção do conhecimento.

\section{AGRADECIMENTOS}

Ao CNPq pelas bolsas do Programa de Iniciação Científica Júnior (PIBIC-EM) que permitiram o desenvolvimento desta pesquisa.

\section{REFERÊNCIAS}

ALRØ, H.; SKOVSMOSE, O. Diálogo e Aprendizagem em Educação Matemática. Tradução Orlando de A. Figueiredo. Belo Horizonte: Autêntica, 2006. 
BORBA, M. C.; OECHSLER, V. Tecnologias na educação: o uso dos vídeos em sala de aula. Revista Brasileira de Ensino de Ciência e Tecnologia, 2. v. 11, 2018.

DOMINGUES, N. S.; BORBA, M. C. Compreendendo o I Festival de Vídeos Digitais e Educação Matemática. Revista da Sociedade Brasileira de Educação Matemática Regional São Paulo, v. 15, n. 18, p. 47-68, 2018.

FREIRE, P. Pedagogia da Autonomia: saberes necessários à prática educativa. 1. ed. São Paulo: Paz e Terra, 1996.

FREIRE, PAULO. Pedagogia do oprimido. 58. ed. Rio de Janeiro: Paz e Terra, 2014.

MORAN, J. Metodologias ativas para uma aprendizagem mais profunda. In: BACICH, L.; MORAN, J. (Org.). Metodologias ativas para uma educação inovadora: uma abordagem teórico-prática. Porto Alegre: Penso, 2018. p. 1-25.

MORAN, J. M. O Vídeo na Sala de Aula. Comunicação e Educação, v. 2, p. 27-35, 1995.

OECHSLER, V. Comunicação Multimodal: produção de vídeos em aulas de Matemática. 2018. 312 f. Tese (Doutorado em Educação Matemática) - Universidade Estadual Paulista Júlio de Mesquita Filho, Rio Claro (SP), 2018.

OECHSLER, V.; FONTES, B. C.; BORBA, M. C. Etapas da produção de vídeos por alunos da educação básica: uma experiência na aula de matemática. Revista Brasileira de Educação Básica, v. 2, n. 1, p. 71-80, 2017.

PEREIRA, J.; BRIGNOL, J.; CEZAR, M. Preconceito na produção de vídeo estudantil. Revista Tecnologias na Educação, v. 28, n. 10, p. 1-10, dez. 2018.

TENA, R. R. El video, una herramienta para la enseñanza. In: PEREIRA, J. (Org.). . Produção de Vídeos nas Escolas: Uma visão Brasil - Itália - Espanha - Equador. Pelotas: ERD Filmes, 2014. p. 71-97.

VARGAS, A.; ROCHA, H. V. DA; FREIRE, F. M. P. Promídia: produção de vídeos digitais no contexto educacional. RENOTE, Revista Novas Tecnologias na Educação , 2. v. 5, 2007.

WATANABE, A.; BALDORIA, T.; AMARAL, C. L. C. O vídeo como recurso didático no ensino de química. RENOTE, Revista Novas Tecnologias na Educação, v. 16, n. 1, p. 1-10, jul. 2018.

ZITKOSKI, J. J. Diálogo/Dialogicidade. In: STRECK, D. R.; REDIN, E.; ZITKOSKI, J. J. (Org.). Dicionário Paulo Freire. 2. ed. Belo Horizonte: Autêntica, 2010. p. 117-118. 